\title{
Formation of Competencies of Specialists in the Field of Welding Through the Possibilities of Distance Online Training
}

\author{
Elisaveta Tasheva \\ University of Transport "Todor Kableshkov" \\ Sofia, Bulgaria \\ etasheva@vtu.bg
}

\author{
Marina Manilova \\ IMSETCH ”Acad. A Balevski” - Bulgarian Academy of \\ Sciences \\ Sofia, Bulgaria \\ mamanil@abv.bg
}

\begin{abstract}
Today the new challenges in the world assign a key role to the distance online education in the formation of knowledge and competencies. The development of Internet technologies provides opportunities for much better distance online education. The use of various digital platforms increases the efficiency and improves the way of delivering information to the students. Different types of multimedia applications improve the perception of the learning material. The subject of this report is the development of a

\section{INTRODUCTION}

The need for coordinated and generally recognized training of welding specialists was realized in 1991 when the European Harmonized System (EHS) for training of welding personnel was launched. Its basic principles are realized through a system of general, mandatory, operational procedures and curricula. The streamlined organization for application of EHS proved so fruitful that it was adopted by the International Institute of Welding (IIW) [1].

Welding in the sense of BSS EN ISO 3834: 2006 is a "special technological process". Ensuring reliable, quality and cost-effective production requires well-trained staff. The training in the field of welding is based on the synchronization with the European requirements and traditions imposed by the application of EHS, which is an initiative of the European Welding Federation (EWF). Currently, Bulgaria is a full member of the two main international institutions in the field of welding, IIW and EWF [1]

Distance learning methods were first applied in teaching at the University of South Africa in 1946. Later, in 1969 the British Open University defined a model for methodology for distance online training of welding specialists at the Institute of Metal Science, Equipment and Technologies with Hydro- and Aerodynamics Centre "Acad. A. Balevski" at BAS.

Keywords - welding, distance online training, internet, remote learning, online learning, e-learning, modern education.

integrating pedagogical methods and multimedia technologies into distance learning. Historically, the forerunner of distance learning realized through some kind of technology was the correspondence learning, which started in Europe and the USA in the mid-19th century. It is designed as training for persons who do not attend classrooms and use mail as a means of delivering education materials. In general, distance learning can be described as learning in which learners and teacher are in different places and communicate with each other through computers or other means of communication. Here is an example definition of this way of learning: "We have distance learning when the teacher and the learners are physically separated and when technology (sound, picture, print, etc.), often in combination with direct communication, is used to make a connection between the two parties." [2-11]

Today, the development of computers allows knowledge to be presented electronically and multiplies the speed of working with information. The information technologies allow this information to be stored, transmitted and disseminated over long distances at any time. These technologies provide new alternative means for 
learning that were unthinkable a few decades ago. Particularly, the achievements of online technologies allow to develop new teaching methods and means of communication that can provide knowledge without the limitations of the traditional on-site training. These new technologies contribute a lot to the development of distance online learning. Currently, due to the existing global pandemic, many educational organizations face various problems related to the onsite learning. Some of these problems can be solved through distance online training.

The Center of Welding at IMSETCH-BAS provides training for welding practitioners, specialists and inspectors.

\section{METHODOLOGY OF THE COURSE FOR DISTANCE ONLINE TRAINING OF WELDING SPECIALISTS}

The concept of "methodology of the course" is related to the process of planning all components of training (curriculum, learning activities, resources, teaching aids, assessment) in their sequence, internal interconnectedness and dynamics, aimed at achieving educational goals. The methodology is realized at two levels: macro- and micro level [12].

At macro level, the planning of the course as a whole is realized: objectives, content, expected results, assessment both of the trainees' achievements and the quality of the course, time schedule (calendar time), instructional time, etc.

At micro level the instructor plans each activity individually (organization, structure and content) and the links between the individual activities so that their sequence leads to the realization of the objectives of the course.

When transforming a course from on-site into online one, we have to consider the characteristic features of distance online learning, which can generally be divided into six steps [12-16]:

- I step, "Diagnosis of the entry level of trainees": involves analysis of the profile of the trainees, the access to technologies, the expected number of trainees.

- II step, "Formulation of training objectives": related to the formation of competencies and skills in a virtual environment.

- III step, "Selection and structuring of educational content": solving issues related to the technologies for presentation of educational content - visualization, dynamization, interactivity, multimedia; how certain learning content can be mastered online; with what technologies to implement the learning activities.

- IV step, "Design of learning activities": designing and describing in detail all the tasks and activities in accordance with the capabilities of the online learning environment.

- V step, "Design of the information-resource provision of the course": the teacher specifies the quality, quantity and depth of the selected information necessary for the formation of competencies by the trainees.

- VI step, "Assessment of trainees' achievements": solving issues such as methodologies for online assessment, assessment software [12-16].

\section{DEVELOPMENT OF DISTANCE ONLINE COURSE FOR TRAINING OF WELDING SPECIALISTS.}

The main objective of the course is to prepare qualified welding specialists for the industry. The training is up-todate and corresponds to the International Harmonized System for training of welding specialists. The accession of Bulgaria to the European Union and the introduction of pan-European requirements for quality assurance of welded joints (regulated in a series of standards) set serious tasks of legal, legal-standardization, structuralorganizational and technical nature, which require synchronizing the training of welding personnel with the European requirements and traditions.

The welding specialists acquire:

- $\quad$ Specialized knowledge in the field of welding;

- Knowledge of the capabilities of modern methods and technologies for welding and their application in modern industrial production;

- Knowledge of control and testing of welded structures;

- Knowledge for independent solution of constructive and technological issues related to the production of welded structures and products;

- Knowledge for the responsibility in manufacture of welded structures and products.

The course was designed at macro level in the following sequence:

- $\quad$ Planning the course structure;

- Defining the learning objectives of the course;

- Defining the expected learning outcomes;

- Main topics of the curriculum;

- $\quad$ Time schedule (calendar time) - start and end of the course; 
- Instructional time for teaching and learning activities;

- Number of trainees;

- $\quad$ Prerequisites for enrollment in the course;

- $\quad$ Assessment: types of assessment methods; the way of forming the final grade of the course; identification of plagiarism.

For the purpose of distance online training course for welding specialists, the Microsoft Teams platform was selected and purchased as part of Microsoft 365 products (Fig. 1).

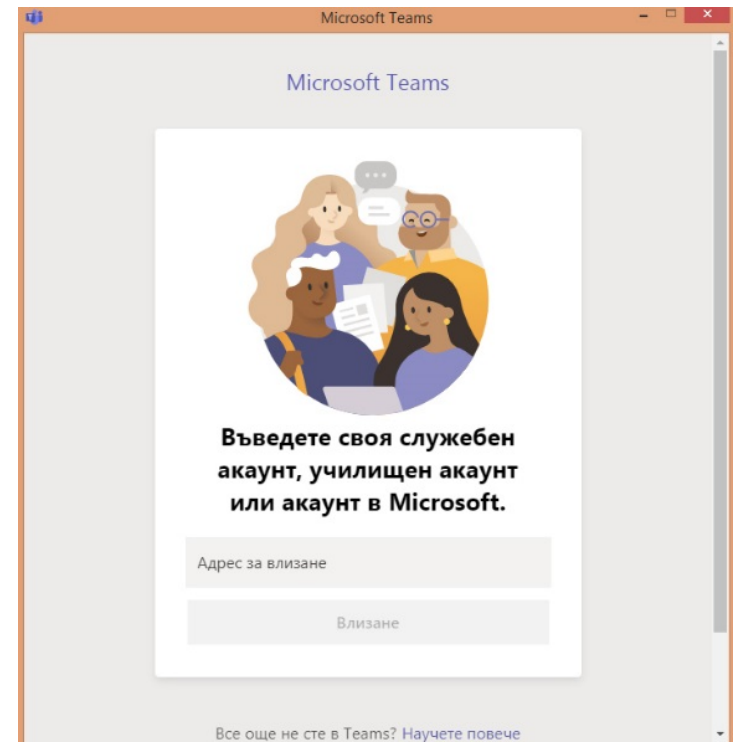

Fig. 1. Microsoft Teams platform for distance online learning.

All teachers and trainees were provided with users' accounts and access to Microsoft Teams. A team of teachers was organized to conduct the course (Fig. 2).

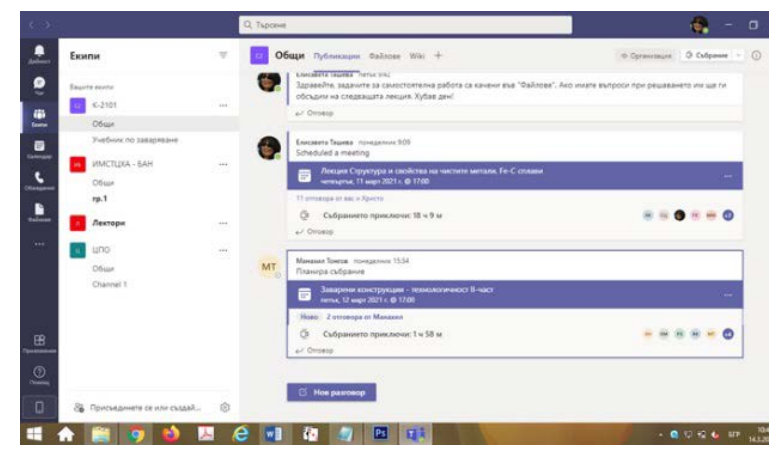

Fig. 2. Team K-2101 to conduct the online training course of welding specialists.

The structure and topics for conducting the course were developed in accordance with the objectives of the training (Fig. 3).

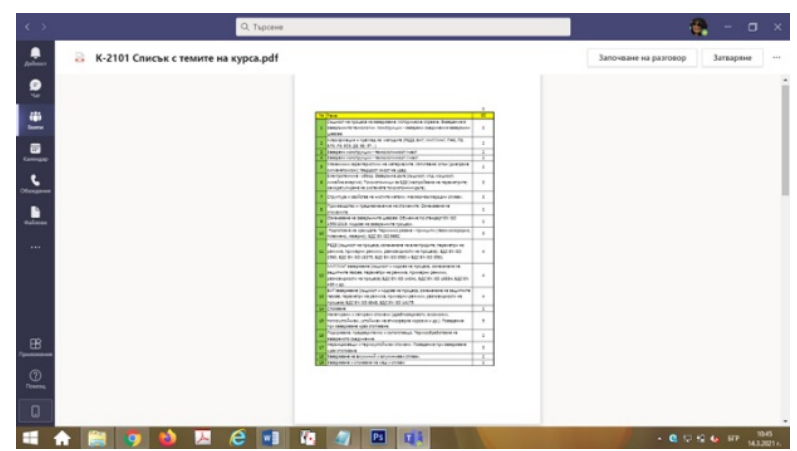

Fig. 3. Structure and topics for conducting the online training course for welding specialists.

The time schedule was developed and uploaded in the calendar of the platform (Fig. 4).

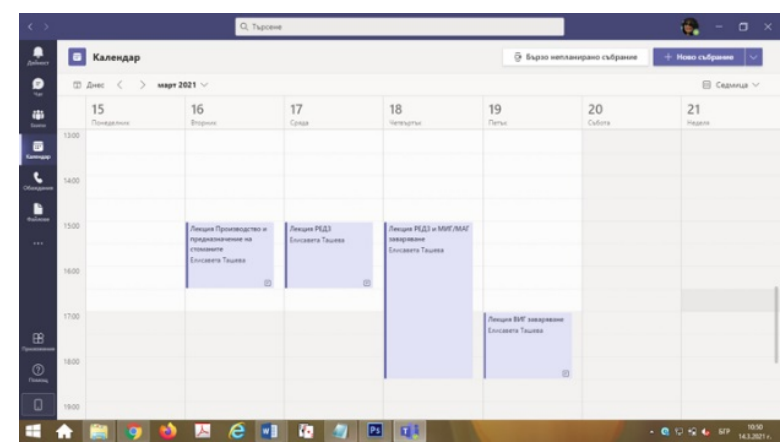

Fig. 4. Time schedule for conducting the course.

All delivered lectures are recorded and uploaded on the platform to facilitate the trainees in their individual preparation (Fig. 5).

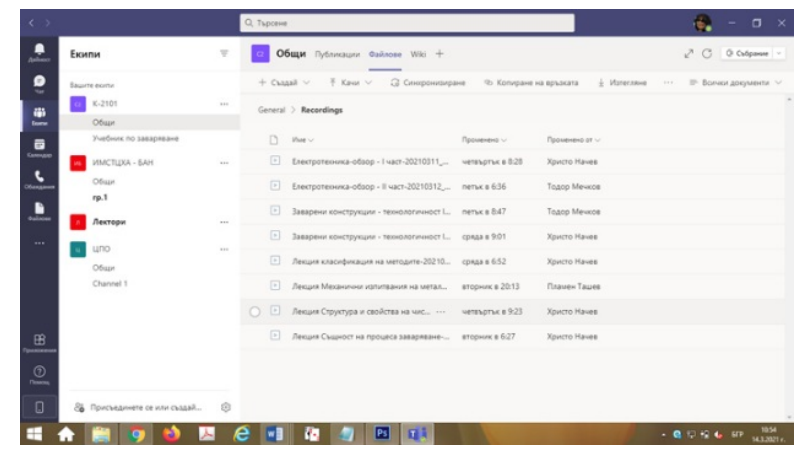

Fig. 5. Video lectures recorded and uploaded on the platform.

Videos illustrating the lecture material are also uploaded on the platform Microsoft Teams (Fig. 6). 


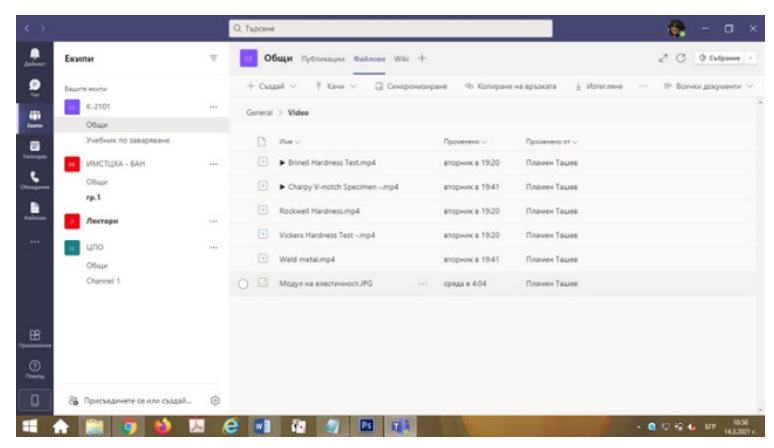

Fig. 6. Illustrating video materials.

The electronic textbook "Welding", which is written mainly by teachers leading the course is also uploaded on the Microsoft Teams platform (Fig. 7).

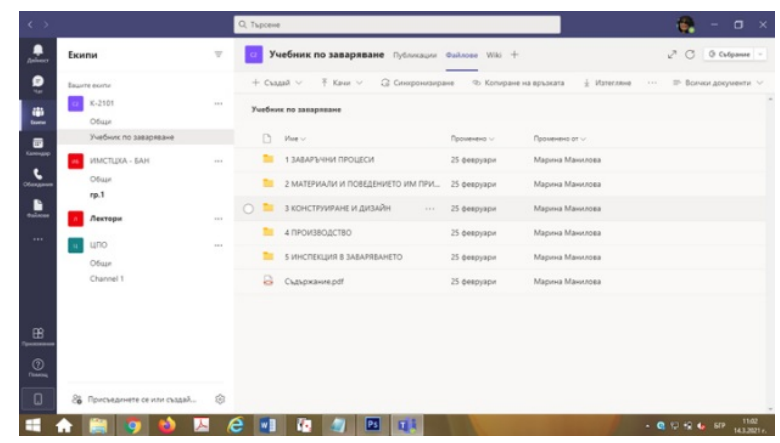

Fig. 7. The electronic textbook "Welding".

At the micro level, each teacher has developed lectures considered with the topics of the course, which in addition to theoretical material contain many examples (pictures and videos) illustrating the material taught. (Fig. 7).

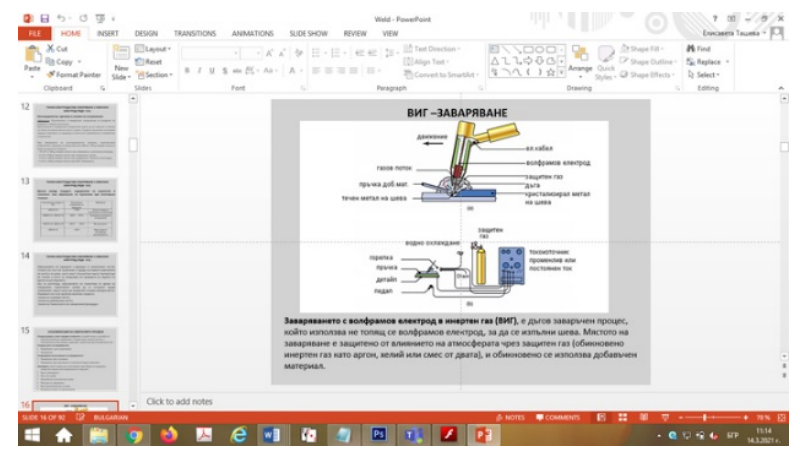

Fig. 8. Lecture material.

Tasks for independent work and preparation of the trainees are also developed (Fig. 9).

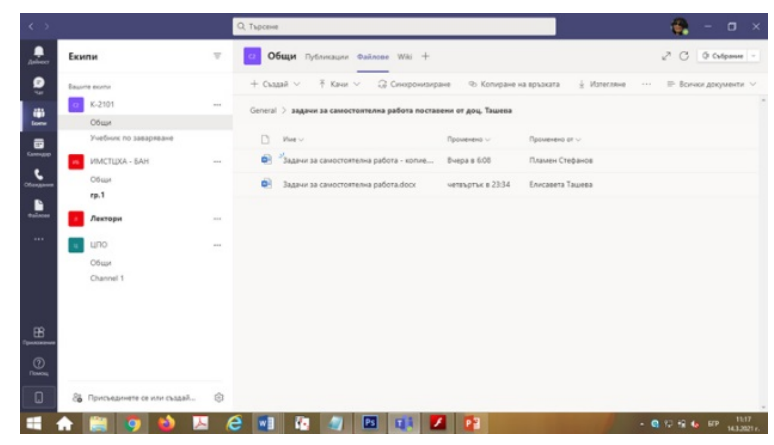

Fig. 9. Tasks for independent work and preparation

\section{CONCLUSION}

The distance online learning offers some very good opportunities for the learners to acquire knowledge at their own pace while providing them with a direct connection with the teacher without time and place restrictions. It reduces the costs required for transport, accommodation and maintenance in another locality. It is especially suitable for the training of active people directly involved in industry. With regard to the teachers, the main advantage is the possibility to update the teaching material, the use of multimedia tools for interactive teaching.

Of course, the distance online learning has its drawbacks, such as the need for additional training to work with the Microsoft Teams platform, and it cannot completely replace the practical training of welding specialists.

For successful formation of competencies of specialists in the field of welding it is recommended to combine both forms, distance online and on-site training.

\section{ACKNOWLEDGMENTS}

A team of leading scientists in the field of welding from the Institute of Metal Science, Equipment and Technologies with Hydroaerodynamics Centre "Acad. A. Balevski" at BAS are working on the possibilities for remote control and control of the welding parameters in real time. The work on Scientific Project KP-06-N37/31: "Study on the possibilities for improving the quality of welding technologies through real-time process analysis" provides a good opportunity to acquire fundamental knowledge about the possibilities for improving the welding technologies and the quality of welded products by remote monitoring of the welding parameters in real time. This enables the trainees to acquire practical knowledge by remotely tracking the welding parameters set in the welding procedure and by online tracking the impact of the deviations from the parameters of the welding mode on the quality of the welded joints. The real-time remote monitoring of the welding parameters and subsequent analysis can improve the quality of distance online training of welding specialists. 


\section{REFERENCES}

[1] M. Beloev, P. Derzhanov, "The European harmonized system for training of welding personnel and its application in Bulgaria", virtual magazine for science, technology and innovation "Machines, Technologies, Materials", issue 1, 2008, 25 (in Bulgarian).

[2] E. Shoikova, V. Denishev, (2002) "Elearning Technology Standards Overview”. In Proceedings, CompSysTech, 2002, pp. 113.

[3] F. Belanger \& D. H. Jordan, (2000) "Evaluation and Implementation of Distance Learning: Technologies, Tools and Techniques”, Idea Group Publishing, Hershey USA, London UK.

[4] N. Campbell, (2001) "E-teaching and its Impact on Teachers”, In Issues in Online Learning Reader.

[5] B. Hall, (1995) "Return on Investment and Multimedia Training”, In Multimedia and Internet Training Newsletter.

[6] B. Hall, (1997) "Web-Based Training”, Published by John Wiley \& Sons, Inc., USA.

[7] J. R. Hill, (1997) "Distance Learning Environments Via the World Wide Web”, In Badrul Khan Web-Based Instruction Educational Technology Publications, Englewood Cliffs, New Jersey.

[8] E. Tasheva, "Possibilities for obtaining basic knowledge in the field of welding through electronic web-based training", ISSN 13123823 Scientific Journal "Mechanics, Transport, Communications", Volume 12 3/1 2014, article № 0988, 2014, pp. from XIII-1 to XIII5 (section "Materials Science and Materials Technologies") (in Bulgarian).

[9] E. Tasheva, "Possibilities for creating and developing web-based and online training in laboratory exercises in Materials science, ISSN 1310-3946, Scientific Proceedings of NTSM, "Days of NonDestructive Testing 2014", iss. 1 (150) and XXVIII National
Conference with International Participation "Defectoscopy`14", Bulgaria, Sozopol, June 9-17, 2014, pp. 207-209 (in Bulgarian).

[10] E. Tasheva, " Model of web-based online learning at the Luleå University Of Technology - Sweden ", ISSN 1310-3946, Scientific Proceedings of NTSM, "Days of Non-Destructive Testing 2014", iss. 1 (150) and XXVIII National Conference with International Participation "Defectoscopy`14", Bulgaria, Sozopol, June 9-17, 2014, pp. 204-206 20 (in Bulgarian).

[11] E. Tasheva, "Formation of students' competencies in the field of non-destructive means of control through the possibilities of webbased online learning", ISSN 1310-3946, Scientific Bulletins of NTSM, International Conference, "Non-destructive testing in modern industry", 3 -5 February 2015, Sofia, collection of reports pp. 56 - 59 (in Bulgarian).

[12] M. Hristova, "Content and scientific-methodical aspects of a master's course for distance learning in "Electronic Business"', Scientific Journal "Mechanics, Transport, Communications", Volume 12 3/2, 2014, Article № 1002, ISSN 1312-3823 (in Bulgarian).

[13] The use of ICT to support innovation and lifelong learning for all A report progress.

[14] Commission staff working document, Brussels, 09/10/2008, SEC(2008)2629 http://www.ifap.ru/pr/2008/n081201c.pdf

[15] R. Peycheva-Forsyth, "E-learning - theory, practice, aspects of pedagogical design”, Journal of the Sofia University of E-learning, 2010 (in Bulgarian).

[16] P. Stefanova "First steps in e-learning in higher mathematics", National Conference "Education in the Information Society", 2012 (in Bulgarian). 